Jurnal Health Sains: p-ISSN: 2723-4339 e-ISSN: 2548-1398

Vol. 3, No. 1, Januari 2022

\title{
PENGARUH PERAN KEPALA UNIT DAN BEBAN KERJA TERHADAP BUDAYA KESELAMATAN PASIEN MELALUI IMPLEMENTASI HANDOVER PERAWAT- FARMASI
}

\author{
Aini Nadhifah, Rokiah Kusumapradja, Nofierni \\ Universitas Esa Unggul, Jakarta, Indonesia \\ Email: nadhifahaini1207@gmail.com,rokiah.kusumapradja@esaunggul.ac.id, \\ nofi.erni@esaunggul.ac.id
}

\begin{tabular}{ll}
\hline INFO ARTIKEL & ABSTRAK \\
\hline Diterima & Penerapan budaya keselamatan pasien merupakan salah satu upaya \\
5 Desember 2021 & Rumah Sakit dalam menjaga pasien untuk tidak mengalami kejadian \\
Direvisi & yang tidak diharapkan. Penelitian ini menggunakan pendekatan \\
15 Desember 2021 & kuantitatif dengan rancangan penelitian desain kausal menggunakan VB- \\
Disetujui & SEM berbasis varian yakni PLS (Partial Least Square), bertujuan untuk \\
25 Januari 2022 & menganalisa pengaruh yang dapat meningkatkan nilai-nilai budaya \\
\hline Kata Kunci: & keselamatan pasien di rumah sakit. Penelitian ini menggunakan sampel \\
peran kepala unit; & jenuh 77 orang (staf perawat ruangan dan farmasi). Hasil penelitian ini \\
beban kerja; & menunjukkan terdapat pengaruh positif peran kepala unit terhadap \\
implementasi & budaya keselamatan pasien, pengaruh negatif beban kerja terhadap \\
handover; budaya & budaya keselamatan pasien, pengaruh positif implementasi handover \\
keselamatan pasien & perawat-farmasi terhadap budaya keselamatan pasien, pengaruh positif \\
& peran kepala unit terhadap implementasi handover perawat-farmasi, \\
& pengaruh positif peran kepala unit terhadap budaya keselamatan pasien \\
& melalui implementasi handover perawat-farmasi sebagai variabel \\
& intervening, dimana hasil pengukuran tstatistik>ttabel dan probabilitas \\
& (pvalue) 0.000<0.05, dan tidak terdapat pengaruh negatif beban kerja \\
& terhadap implementasi handover perawat-farmasi, serta tidak terdapat \\
& pengaruh negatif beban kerja terhadap budaya keselamatan pasien \\
& melalui implementasi handover perawat-farmasi sebagai variabel \\
& intervening dimana hasil tstatistik<ttabel dan probabilitas (pvalue) \\
& $>0.05$. Berdasarkan hasil penelitian maka implikasi dalam penelitian ini \\
& menunjukkan pengaruh peran kepala unit terhadap budaya keselamatan \\
pasien melalui implementasi handover sebagai perencana, & pengorganisasian, ketenagaan, pengarahan dan pengawasan dalam \\
& pelaksanaan handover yang efektif dan efisien guna meningkatkan \\
& keselamatan pasien di rumah sakit.
\end{tabular}

\section{ABSTRACT}

The application of patient safety culture is one of the hospital's efforts in keeping patients from experiencing unexpected events. This study uses a quantitative approach with a causal design research design using a variant-based VB-SEM, PLS (Partial Least Square), aimed at analyzing influences that can improve the cultural values of patient safety in hospitals. The study used a saturated sample of 77 people (room nurse staff and pharmacy). The results of this study showed that there was a positive influence on the role of the head of the unit on the culture of patient safety, the negative influence of workload on patient safety

How to cite:

E-ISSN:

Published by:
Nadhifah. A. et.al (2022) Pengaruh Peran Kepala Unit dan Beban Kerja terhadap Budaya Keselamatan Pasien Melalui Implementasi Handover Perawat-Farmasi. Jurnal Health Sains 3(1). https://doi.org/10.46799/jhs.v3i1.391 $2723-6927$

Ridwan Institute 
culture, the positive influence of the implementation of nurse-pharmacy handovers on patient safety culture, the positive influence of the role of the head of the unit on the implementation of nurse-pharmacy handovers.positive influence of the role of the head of the unit on the patient safety culture through the implementation of nurse-pharmacy handover as an intervening variable, where the results of tstatistic $>$ ttabel and probability (pvalue) measurements $0,000<0.05$, and there is no negative influence of workload on the implementation of nurse-pharmacy handovers, and there is no negative influence of workload on patient safety culture through the implementation of nurse-

Keywords: the role of the head of the unit; workload; implementation of handover; Patient safety culture pharmacy handovers as intervening variables where results are tstatistics<ttabel and probability (pvalue) $>0.05$. Based on the results of the study, the implications in this study show the influence of the role of the head of the unit on the culture of patient safety through the implementation of handovers as planners, organizing, military, directing and supervision in the implementation of effective and efficient handovers to improve patient safety in hospitals.

\section{Pendahuluan}

Keselamatan pasien (patient safety) di rumah sakit adalah suatu sistem yang diterapkan untuk mencegah terjadinya cedera akibat perawatan medis dan kesalahan pengobatan melalui suatu sistem assessment resiko, identifikasi dan pengelolaan faktor risiko, pelaporan dan analisis insiden, kemampuan belajar dan tindak lanjut dari insiden serta implementasi solusi untuk meminimalkan timbulnya risiko (Peraturan Menteri Kesehatan RI, 2011). Seiring berkembangnya asuhan keperawatan kesehatan di Indonesia, guna meningkatkan keselamatan pasien dari waktu ke waktu, maka model tradisional yang biasa digunakan dalam dunia Perumah sakitan di Indonesia diubah menjadi Patient Centered Care, dimana bukan lagi dokter yang menjadi pusat melainkan pasien yang menjadi unit sentral menyebabkan asuhan pasien harus terintegrasi dengan DPJP (dokter penanggung jawab pasien) sebagai leadernya. DPJP melakukan Koordinasi, Kolaborasi, Review, Sintesis, Interpretasi, dan Integrasi Asuhan komprehensif terhadap setiap pasien yang dirawat, membuat komunikasi efektif akan sangat berperan besar dalam pelaksanaan Patient Centered Care terutama antar PPA (Profesional Pemberi Asuhan) dalam memberikan asuhan terhadap pasien. Guna meningkatkan keselamatan pasien, komunikasi antar PPA perlu menjadi perhatian khusus bagi rumah sakit dalam meningkatkan keselamatan pasien, mutu layanan rumah sakit dan demi berjalannya asuhan keperawatan berdasarkan komunikasi yang efektif yang nantinya akan sangat berpengaruh bagi kelanjutan tindakan di setiap antar layanan jasa.

Pelaksanaan handover dengan menggunakan komunikasi efektif dapat meminimalkan waktu pelaksanaan handover dan informasi pasien yang disampaikan lebih akurat dan jelas dengan tingkat budaya keselamatan pasien yang menunjukkan adanya kenaikan positif (Achrekar et al., 2016) dan (Abela-Dimech \& Vuksic, 2018). Dengan demikian penggunaan komunikasi efektif dalam pelaksanaan handover, dapat memberikan informasi yang disampaikan menjadi lebih lengkap untuk kelanjutan PPA dalam meberikan asuhan perawatan pasien dalam meningkatkan keselamatan pasien.

IOM (Institute of Medicine) secara terbuka menyatakan bahwa paling sedikit 44.000 bahkan 98.000 pasien meninggal dirumah sakit dalam satu tahun akibat dari kesalahan medis (medical errors) yang sebetulnya bisa dicegah. Kemudian pada 
tahun 2000, IOM menerbitkan laporan To Err is Human: Building a Safer Health System, laporan tersebut mengemukakan penelitian di beberapa rumah sakit di Utah dan Colorado serta New York tentang KTD (Kejadian Tidak Diharapkan). Di Utah dan Colorado ditemukan KTD sebanyak 2,9\%, 6,6\% diantaranya menyebabkan kematian, sementara di New York KTD sebesar 3,7\% dengan angka kematian mencapai 13,6\%. WHO pada tahun 2004 mengumpulkan angka-angka penelitian rumah sakit di berbagai negara: Amerika, Inggris, Denmark, dan Australia, ditemukan KTD dengan rentang 3,2 -16,6\% (IOM, 2009). Hal ini menunjukkan masih tingginya kejadian insiden keselamatan pasien yang salah satunya dapat disebabkan karena komunikasi yang tidak efektif. Komunikasi tidak efektif dapat menyebabkan terjadinya insiden keselamatan pasien serta dapat berkontribusi terhadap kesalahan dalam perawatan dan insiden keselamatan pasien. Fenomena yang sering dijumpai dalam pelayanan keperawatan di rumah sakit terkait komunikasi handover adalah kurangnya informasi yang disampaikan, salah persepsi, isi yang disampaikan tidak fokus terhadap masalah pasien (AHRQ, 2014). Systematic review Mardis et al (2016) mengemukakan masalah yang terjadi terkait handover adalah kesalahan pengobatan, kematian, kesalahan prosedur, infeksi nosokomial. Masalah lain yang dapat muncul seperti penundaan pelaporan kritis, keterlambatan dan ketidaksinambungan asuhan, perawatan yang tidak tepat dan penambahan waktu perawatan (National Clinical Effectiveness Commitee, 2014). Handover merupakan komunikasi transfer informasi dan tanggung jawab dari satu penyedia layanan ke penyedia layanan lain. Abdurrahman \& Garcia (2016) mengemukakan bahwa handover merupakan proses menyampaikan informasi pasien dan transfer tanggung jawab antar pemberi layanan, dan dalam Yu et al (2017) handover berupa pemindahan informasi, tanggung jawab dan wewenang dari satu penyedia layanan kesehatan ke penyedia layanan lain.

Dalam penelitian Cecep Triwibowo et al (2016) handover dapat dilakukan seperti: handover antar shift, handover antar unit keperawatan, handover antar unit rawatan dengan unit pemeriksaaan diagnostik, handover dengan bagian obat-obatan dan handover antar fasilitas kesehatan. Sehingga handover dapat diartikan sebagai bentuk komunikasi transfer informasi dan tanggung jawab antar pemberi layanan, antar profesi dan antar unit layanan. Dimana komunikasi efektif akan sangat berperan penting dalam menentukan keberhasilan informasi antar PPA terutama pada saat handover selama memberi asuhan perawatan pada pasien.

Berdasarkan struktur organisasi kepala unit yang menjabat di unit farmasi ditemukan adanya posisi rangkap jabatan, sehingga penulis mengidentifkasi adanya beban kerja kepala unit dalam menentukan standar baku handover antara perawat dan farmasi dalam melakukan komunikasi serah terima, terbukti dengan adanya laporan insiden Kejadian Nyaris Cidera pada tahun 2019, dan belum adanya standar baku terkait form catatan pemberian obat serta buku ekspedisi serah terima di unit farmasi. Melihat dari fenomena yang ada penulis mengidentifikasi akan adanya potensi retur obat yang tinggi serta Kejadian Nyaris Cidera dapat terjadi kembali di ruang perawatan dimana tidak ada double checker antara perawat dan farmasi dalam memberikan obat kepada pasien selama di ruang perawatan.

Perawat dan staf farmasi di Rumah Sakit X memiliki beberapa tuntutan pekerjaan pokok, meliputi: melaksanakan pengkajian keperawatan dasar kepada pasien, melaksanakan analisis data untuk merumuskan diagnosa keperawatan kepada pasien, merencanakan tindakan keperawatan sederhana kepada pasien, melaksanakan implementasi keperawatan, melaksanakan 
evaluasi keperawatan secara sederhana pada pasien, serta melaksanakan tugas khusus di unit pelayanan kesehatan yang mempunyai resiko tinggi untuk unit keperawatan. Sedangkan dalam unit farmasi dengan jumlah staf saat ini harus melaksanakan pengkajian telaah resep, penginputan obat ke dalam komputer dikarenakan belum adanya elektronik resep, mengecheck obat retur pasien pulang, mengkonfirmasi obat apabila terdapat kekosongan, dan menyiapkan permintaan obat berdasarkan resep, ditambah dengan jadwal lembur yang sering dilakukan, terbukti dengan ada banyaknya form lembur perawat dan farmasi di bagian SDM yang mencatat bahwa petugas bekerja melebihi batas jadwal shift kerjanya. Berdasarkan kondisi ini penulis mengidentikasi pelaksanaan budaya keselamatan pasien di rumah sakit dapat berpotensi menurun akibat adanya faktor tuntutan pekerjaan dan kelelahan.

\section{Metode Penelitian}

Desain penelitian ini menggunakan pendekatan kuantitatif dan rancangan penelitian ini adalah desain kausal. Menurut Indrawati (2015) bahwa penelitian dengan desain kausal merupakan penelitian yang dilakukan apabila peneliti ingin menggambarkan penyebab dari suatu masalah baik dilaksanakan dengan melalui eksperimen maupun non eksperimen. Penelitian kuasal digunakan untuk menganalisis hubungan antara satu variabel dengan variabel lainnya. Berdasarkan tujuan penelitian, maka penelitian ini bertujuan untuk mengidentifikasi faktor-faktor yang berhubungan dengan budaya keselamatan pasien, serta menentukan langkah-langkah untuk memperbaiki dan meningkatkan budaya keselamatan pasien di Rumah Sakit $\mathrm{X}$.

Populasi merupakan keseluruhan dari objek penelitian berupa kumpulan atau merupakan wilayah generalisasi yang terdiri atas objek atau subjek yang memiliki kualitas dan karakteristik tertentu yang diterapkan oleh peneliti untuk dipelajari kemudian ditarik kesimpulan (Sugiyono, 2016). Populasi dalam penelitian ini adalah perawat pelaksana di instalasi rawat inap dan petugas farmasi di Rumah Sakit X.

Sampel adalah bagian dari jumlah dan karakteristik yang dimiliki oleh populasi (Sugiyono, 2016). Unsur tersebut berupa orang, benda, perusahaan, atribut, atau unitunit apa saja yang terkandung dalam objek penelitian Hasyim \& Anindita (2009) Peneliti menggunakan teknik pengambilan yang dikembangkan. Sampel pada penelitian ini adalah seluruh petugas staff perawat di ruang perawatan sebanyak 68 responden dan 9 staf farmasi di Rumah Sakit X.

Populasi dalam penelitian ini adalah petugas perawat rawat inap dan petugas farmasi yang bekerja di Rumah Sakit X berjumlah 77 orang (68 perawat dan 9 Farmasi).

Sampel harus memenuhi kriteria inklusi dan kriteria eksklusi, yaitu sebagai berikut:

1. Kriteria Inklusi:

a. Merupakan Tenaga Kesehatan Perawat Rumah Sakit X yang bertugas di Ruang Rawat Inap

b. Merupakan Tenaga Kesehatan Farmasi Rumah Sakit X

c. Bersedia diwawancara dan mengisi kuesioner

2. Kriteria Eksklusi:

a. Koordinator Unit yakni Ka Perawat dan Ka Unit Farmasi

b. Petugas yang sedang cuti melahirkan atau terpapar covid-19

Pengambilan sampel harus sesuai dengan kriteria tersebut, karena akan berpengaruh pada variabel yang akan diteliti. Penentuan jumlah sampel dapat dihitung dari populasi tertentu yang sudah diketahui jumlahnya. Pengambilan sampel untuk 
penelitian menurut Arikunto (2010), jika subjeknya kurang dari 100 orang sebaiknya diambil semuanya, jika subjeknya besar atau lebih dari 100 orang dapat diambil $10-15 \%$ atau $20-25 \%$ atau lebih.

Pengampilan sample dalam penelitian ini menggunakan teknik total sampling, Sugiyono (2013) mengatakan bahwa total sampling adalah teknik penentuan sampel bila semua anggota populasi digunakan sebagai sampel. Sehingga sample dalam penelitian ini sebanyak 77 orang (68 perawat dan 9 Farmasi).

Hipotesis dalam penelitian ini dapat dilihat pada Gambar 1.

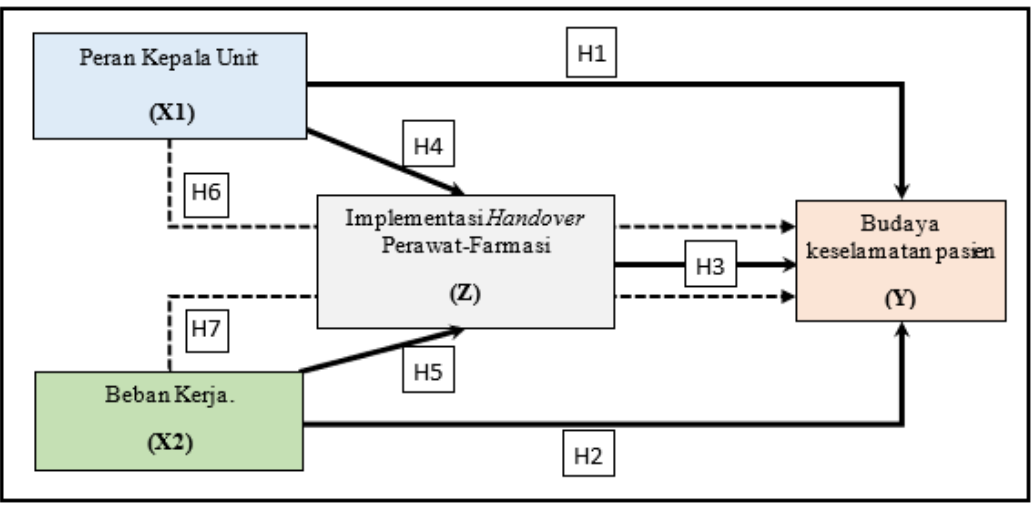

Gambar 1

Konstelasi Hipotesis Penelitian

Gambar 1 menunjukkan gambaran hipotesis meliputi:

Hipotesis 1:

Ho1: Tidak terdapat pengaruh positif Peran Kepala Unit terhadap Budaya Keselamatan Pasien.

Ha1: Terdapat pengaruh positif Peran Kepala Unit terhadap Budaya Keselamatan Pasien

Hipotesis 2:

Ho2: Tidak terdapat pengaruh negatif Beban Kerja terhadap Budaya Keselamatan Pasien.

Ha2: Terdapat pengaruh negatif Beban Kerja terhadap Budaya Keselamatan Pasien.

Hipotesis 3:

Ho3: Tidak terdapat pengaruh positif Implementasi Handover PerawatFarmasi terhadap Budaya Keselamatan Pasien

Ha3: Terdapat pengaruh positif Implementasi Handover Perawat-Farmasi terhadap Budaya Keselamatan Pasien.

Hipotesis 4:

Ho4: Tidak terdapat pengaruh positif Peran Kepala Unit terhadap Implementasi Handover Perawat-Farmasi
Ha4: Terdapat pengaruh positif Peran Kepala Unit terhadap Implementasi Handover Perawat-Farmasi

Hipotesis 5:

Ho5: Tidak terdapat pengaruh negatif Beban Kerja terhadap Implementasi Handover Perawat-Farmasi.

Ha5: Terdapat pengaruh negatif Beban Kerja terhadap Implementasi Handover Perawat-Farmasi

Hipotesis 6:

Ho6: Tidak terdapat pengaruh positif Peran Kepala Unit terhadap Budaya Keselamatan Pasien melalui Implementasi Handover PerawatFarmasi

Ha6: Terdapat pengaruh positif Peran Kepala Unit terhadap Budaya Keselamatan Pasien melalui Implementasi Handover Perawat-Farmasi

Hipotesis 7:

Ho7: Tidak terdapat pengaruh negatif Beban Kerja terhadap Budaya Keselamatan Pasien melalui Implementasi Handover Perawat-Farmasi

Ha7: Terdapat pengaruh negatif Beban Kerja terhadap Budaya Keselamatan Pasien 
melalui Implementasi Handover Perawat-Farmasi

Teknik pengumpulan data untuk mengidentifikasi faktor-faktor yang berhubungan melalui kuisioner yang dibagikan kepada responden dengan mendatangi perawat dan farmasi yang memenuhi kriteria inklusi. Kuisioner/ Angket merupakan metode pengumpulan data yang dilakukan dengan menggunakan pertanyaan pilihan terhadap suatu pernyataan yang dijawab oleh orang yang meliputi sasaran kuisioner dalam penelitian ini orang atau responden yang diberikan kuisioner adalah petugas ruang perawatan dan farmasi, hal pertama yang akan dilakukan peneliti adalah membacakan lembar informed consent, selanjutnya responden menandatangani persetujuan keikutsertaan dalam penelitian.
Kemudian kuesioner/ angket diberikan kepada responden untuk diisi, dan apabila ada yang kurang jelas dapat ditanyakan kepada peneliti.

Instrumen penelitian merupakan alat atau fasilitas yang digunakan peneliti guna mempermudah dalam mengumpulkan data serta proses penelitian dengan hasil yang didapat menjadi lebih baik, dalam arti lebih cermat, lengkap dan sistematis sehingga dapat dioleh dengan mudah. Variasi jenis instrumen penelitian adalah angket/kuisioner, ceklist, atau daftar centang, pedoman wawancara, pedoman pengamatan (Arikunto, 2010).

Kuisioner/ angket penelitian disusun dengan cara mengajukan pernyataan tertutup serta pilihan jawaban untuk disampaikan kepada sampel penelitian dengan skala Likert, dengan kriteria sebagai berikut:

Tabel 1

Skala Interval

\begin{tabular}{cccc}
\hline No & Jawaban & \multicolumn{2}{c}{ Bobot (Skor) } \\
\cline { 3 - 4 } & & Positif & Negatif \\
\hline 1 & Sangat Setuju & 5 & 1 \\
\hline 2 & Setuju & 4 & 2 \\
\hline 3 & Ragu-ragu & 3 & 3 \\
\hline 4 & Tidak Setuju & 2 & 4 \\
\hline 5 & Sangat Tidak Setuju & 1 & 5 \\
\hline
\end{tabular}

Sumber: (Sugiyono, 2013)

\section{Hasil dan Pembahasan}

Pada penelitian ini akan disajikan mengenai data penelitian yang diperoleh dari hasil jawaban responden, proses pengolahan data, dan analisis hasil pengolahan data. Hasil pengolahan data selanjutnya akan digunakan sebagai dasar untuk analisis dan menjawab hipotesis yang diajukan. Analisis yang digunakan adalah structural equation modeling (SEM) dengan partial least squares (PLS).

Penelitian ini dilakukan dengan menyebarkan kuisioner kepada 77 orang yang bekerja di Rumah Sakit X yang terdiri dari 68 orang perawat dan 9 orang bagian farmasi. Dari hasil penyebaran kuisioner instrument penelitian, diperoleh beberapa karakteristik berdasarkan jenis kelamin, jabatan, masa kerja dan pendidikan terakhir, yang disajikan pada tabel 2 .

Berdasarkan jenis kelamin, perempuan mendominasi dalam pekerjaan perawat dan farmasi di RS X dikarenakan profesi perawat dan farmasi biasa lebih diminati oleh perempuan. Berdasarkan rata rata lamanya masa kerja, hampir seluruh responden di rumah sakit $\mathrm{X}$ dapat dinilai memiliki pengalaman kompetensi yang cukup dalam melayani pasien. Dan berdasarkan pendidikan responden dirumah sakit, seluruh responden memiliki pendidikan berdasarkan kemampuan kompetensinya dalam melaksanakan job desc pekerjaannya. 
Pengaruh Peran Kepala Unit dan Beban Kerja terhadap Budaya Keselamatan Pasien Melalui Implementasi Handover Perawat-Farmasi

Tabel 2

Karakteristik Demografi Data Responden (N=77)

\begin{tabular}{|c|c|c|c|}
\hline No & $\begin{array}{c}\text { Karakteristik } \\
\text { Responden }\end{array}$ & Frekuensi & Presentase (\%) \\
\hline \multirow{3}{*}{1} & Jenis Kelamin & & \\
\hline & Laki-Laki & 7 & 9.09 \\
\hline & Perempuan & 70 & 90.91 \\
\hline \multirow{4}{*}{2} & Jabatan & & \\
\hline & Perawat & 66 & 85.71 \\
\hline & Koor. Perawat & 2 & 2.60 \\
\hline & Asisten Apoteker & 9 & 11.69 \\
\hline \multirow{5}{*}{3} & Masa Kerja & & \\
\hline & $<1$ Tahun & 4 & 5.19 \\
\hline & 1-3 Tahun & 52 & 67.53 \\
\hline & 4-6 Tahun & 10 & 12.99 \\
\hline & 7-10 Tahun & 11 & 14.29 \\
\hline \multirow{8}{*}{4} & Pendidikan Terakhir & & \\
\hline & SMKF & 3 & 3.90 \\
\hline & D3 Keperawatan & 48 & 62.33 \\
\hline & D4 Keperawatan & 1 & 1.30 \\
\hline & D3 Farmasi & 4 & 5.19 \\
\hline & S1 Ners & 18 & 23.38 \\
\hline & S1 Farmasi & 2 & 2.60 \\
\hline & S1 Keperawatan & 1 & 1.30 \\
\hline
\end{tabular}

Sumber: Hasil Pengolahan Data, 2021

Penelitian ini bertujuan untuk menguji pengaruh dari faktor-faktor seluruh variabel yang terlibat dalam penelitian ini, yaitu variabel peran kepala unit dan beban kerja sebagai variabel independent, implementasi handover perawat farmasi sebagai variabel intervening dan budaya keselamatan pasien sebagai variabel dependent. Evaluasi model dalam pengembangan teori ini dalam PLS terdiri dari dua tahap, yaitu evaluasi outer model atau model pengukuran (measurement model) dan evaluasi inner model atau model struktural (structural measurement). Evaluasi terhadap model pengukuran dikelompokkan menjadi evaluasi terhadap model reflektif dan formatif. Berikut hasil model penelitian yang dapat dilihat pada Gambar 2

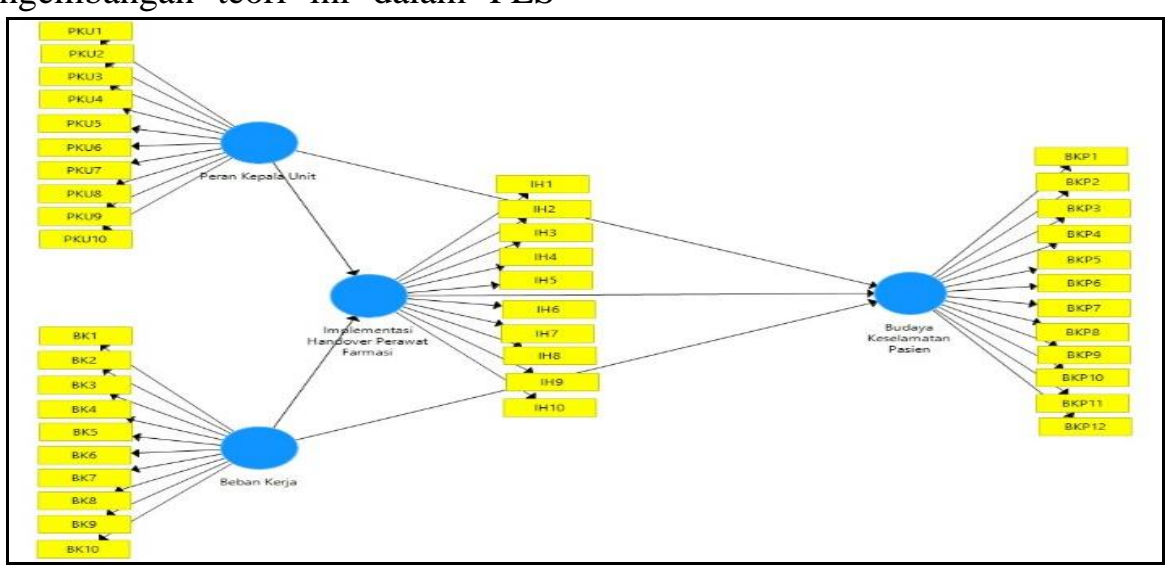

Gambar 2

Pengembangan Model PLS 
Pengaruh Peran Kepala Unit dan Beban Kerja terhadap Budaya Keselamatan Pasien Melalui Implementasi Handover Perawat-Farmasi

1. Outer Model (Model Pengukuran)

Model pengukuran merupakan pengukuran untuk menilai validitas dan reliabilitas model, dimana dalam outer model menguji indikator mana saja yang merupakan pembentuk dari variabel laten dalam penelitian ini. Melalui proses iterasi algoritma, parameter model pengukuran (validitas konvergen, validitas diskriminan, composite realibility dan cronbach's alpha) diperoleh, termasuk nilai $\mathrm{R}^{2}$ sebagai parameter ketepatan model prediksi. Berikut hasil outer model yang dapat diketahui pada Gambar 3.

a. Validitas konvergen

Validitas konvergen dilakukan untuk mengukur tingkat akurat sebuah item atau sekumpulan item. Indikator yang akan digunakan untuk pada penelitian ini adalah factor loading (FL). Apabila nilai FL lebih besar dari 0,7 item yang di ukur dinyatakan valid average variance extracted (AVE) > 0.5 , maka item pada variabel tersebut di anggap memiliki validitas konvergen yang cukup. Berdasarkan hasil pengolahan data, maka diperoleh hasil convergent validity, sebagai berikut:

Berdasarkan hasil Gambar 3 convergent validity pada gambar outer model penelitian, diperoleh bahwa terdapat beberapa indikator variabel yang memiliki nilai loading factor $<0.700$, sehingga perlu dieliminasi dan dilakukan estimasi ulang sampai diperoleh hasil yang valid.

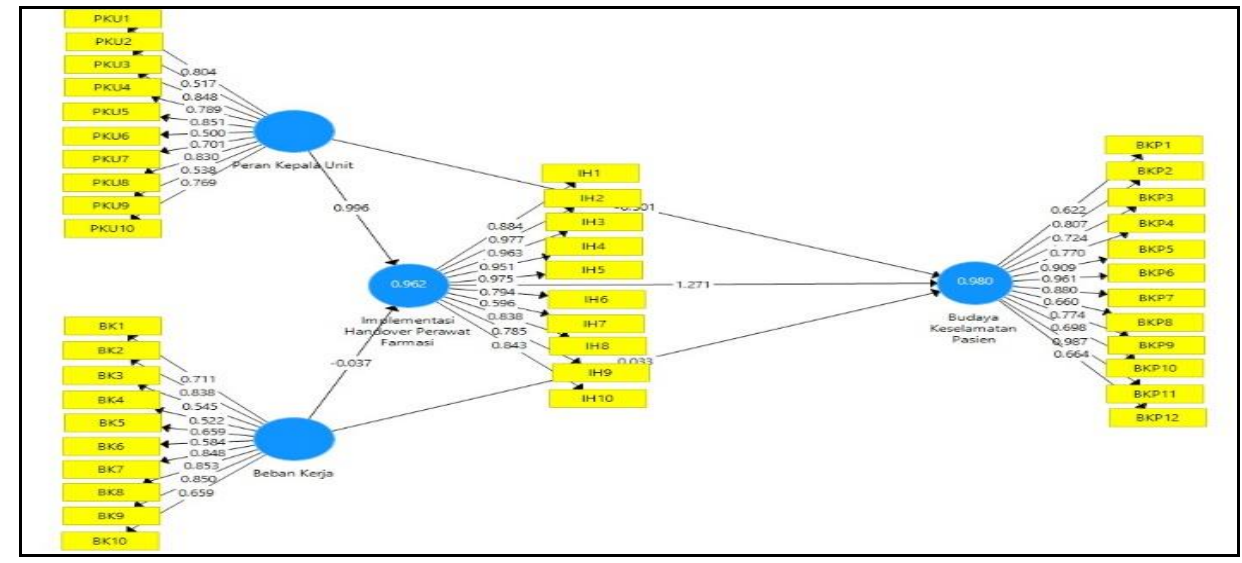

Gambar 3

Outer Model Penelitian

Tabel 3

Convergent Validity (Evaluasi)

\begin{tabular}{cllcc}
\hline Variabel & \multicolumn{1}{c}{ Indikator } & Kode Item & $\begin{array}{c}\text { Nilai } \\
\text { LF }\end{array}$ & Keputusan \\
\hline \multirow{2}{*}{$\begin{array}{c}\text { Peran } \\
\text { Kepala Unit } \\
(\text { XI) }\end{array}$} & 1. Perencanaan & PKU1 & 0.824 & Valid \\
\cline { 2 - 5 } & 2. Pengaturan Staf & PKU3 & 0.888 & Valid \\
\cline { 2 - 5 } & 3. Pengarahan & PKU4 & 0.814 & Valid \\
\cline { 2 - 5 } & 4. Pengendalian & PKU5 & 0.893 & Valid \\
\cline { 2 - 5 } & $\begin{array}{l}\text { 5. Mendorong Kerjasama dan } \\
\text { Partisipasi }\end{array}$ & PKU7 & 0.724 & Valid \\
\cline { 2 - 5 } & $\begin{array}{l}\text { 6. Mengkoordinasikan } \\
\text { Kegiatan }\end{array}$ & PKU8 & 0.868 & Valid \\
\cline { 2 - 5 } & $\begin{array}{l}\text { 7. Evaluasi Hasil Penampilan } \\
\text { Kerja Staf }\end{array}$ & PKU10 & 0.791 & Valid \\
\hline
\end{tabular}


Pengaruh Peran Kepala Unit dan Beban Kerja terhadap Budaya Keselamatan Pasien Melalui Implementasi Handover Perawat-Farmasi

\begin{tabular}{|c|c|c|c|c|}
\hline \multirow{3}{*}{$\begin{array}{l}\text { Beban Kerja } \\
\text { (X2) }\end{array}$} & 1. Pekerjaan yang Berlebihan & $X^{\top}$ & 0.915 & Valid \\
\hline & $\begin{array}{l}\text { 2. Perubahan-perubahan dalam } \\
\text { Pekerjaan }\end{array}$ & BK7 & 0.803 & Valid \\
\hline & $\begin{array}{l}\text { 3. Konflik Antar Pribadi dan } \\
\text { antar kelompok dan } \\
\text { seterusnya }\end{array}$ & BK8 & 0.984 & Valid \\
\hline \multirow{4}{*}{$\begin{array}{c}\text { Implementasi } \\
\text { Handover } \\
\text { Perawat (Z) }\end{array}$} & 1. Introduction & IH1 & 0.921 & Valid \\
\hline & 2. Assesment & IH3 & 0.976 & Valid \\
\hline & 3. Situation & IH4 & 0.963 & Valid \\
\hline & 4. Safety Concern & IH5 & 0.971 & Valid \\
\hline \multirow[t]{5}{*}{$\begin{array}{c}\text { Budaya } \\
\text { Keselamatan } \\
\text { Pasien }(\mathbf{Y})\end{array}$} & $\begin{array}{l}\text { 1. Umpan Balik dan } \\
\text { Komunikasi mengenai } \\
\text { informasi atau kejadian } \\
\text { saat pelayanan di } \\
\text { ruangan/unit. Atau pada } \\
\text { saat sedang melakukan } \\
\text { Operan (handover) antar } \\
\text { rekan kerja antar PPA }\end{array}$ & BKP2 & 0.883 & Valid \\
\hline & 2. Pengaturan Staff & BKP5 & 0.901 & Valid \\
\hline & $\begin{array}{l}\text { 3. Tidak Adanya respon } \\
\text { hukuman untuk kesalahan } \\
\text { penyampaian komunikasi }\end{array}$ & BKP6 & 0.966 & Valid \\
\hline & 4. Kerjasama Tim dalam Unit & BKP9 & 0.895 & Valid \\
\hline & $\begin{array}{l}\text { 5. Persepsi Keseluruhan } \\
\text { tentang pelaksanaan } \\
\text { budaya keselamatan pasien }\end{array}$ & BKP11 & 0.982 & Valid \\
\hline
\end{tabular}

Selanjutnya pengujian convergent validity dengan metode nilai average variance extracted (AVE), dapat dilihat pada Tabel 4.

Tabel 4

Average Variance Extracted (AVE)

\begin{tabular}{cc}
\hline Variabel & Average Variance Extraced (AVE) \\
\hline Peran Kepala Unit & 0.69 \\
\hline Beban Kerja & 0.817 \\
\hline $\begin{array}{c}\text { Implementasi Handover Perawat } \\
\text { Farmasi }\end{array}$ & 0.919 \\
\hline Budaya Keselamatan Pasien & 0.817 \\
\hline
\end{tabular}

Tabel 4 menunjukkan hasil bahwa seluruh variabel memiliki nilai AVE >0.500, hal ini menunjukan bahwa variabel yang digunakan untuk penelitian memiliki convergent validity yang baik.

b. Validitas Diskriman

Uji validitas diskriminan dinilai berdasarkan dari cross loading dengan pengukuran dan konstruknya. Metode lain yang digunakan untuk menilai sebuah validitas diskriminan adalah dengan cara membandingkan akar AVE untuk setiap konstruk dengan korelasi antara konstruk yang lainnya dalam model.

Tabel 4 menunjukkan hasil discriminant validity dengan cross loading diperoleh bahwa masing- 
masing indikator di setiap variabel memiliki nilai cross loading terbesar pada variabel yang dibentuk, bila dibandingkan dengan nilai variabel lainnya. Dari nilai tersebut dinyatakan bahwa indikator- indikator yang digunakan pada penelitian ini merupakan discriminant validity yang baik.

Tabel 5

Diskriminan Validity (Cross Loading)

\begin{tabular}{lcccc}
\hline Indikator & $\begin{array}{c}\text { Beban Kerja } \\
(\mathbf{B K})\end{array}$ & $\begin{array}{c}\text { Budaya } \\
\text { Keselamatan } \\
\text { Pasien (BKP) }\end{array}$ & $\begin{array}{c}\text { Implementasi } \\
\text { Handover } \\
\text { Perawat } \\
\text { Farmasi (IH) }\end{array}$ & $\begin{array}{c}\text { Peran Kepala } \\
\text { Unit (PKU) }\end{array}$ \\
\hline BK1 & 0.915 & 0.267 & 0.362 & 0.283 \\
\hline BK7 & 0.803 & 0.214 & 0.256 & 0.259 \\
\hline BK8 & 0.984 & 0.304 & 0.393 & 0.346 \\
\hline BKP11 & 0.318 & 0.982 & 0.975 & 0.877 \\
\hline BKP2 & 0.144 & 0.883 & 0.770 & 0.875 \\
\hline BKP5 & 0.230 & 0.901 & 0.888 & 0.691 \\
\hline BKP6 & 0.319 & 0.966 & 0.954 & 0.859 \\
\hline BKP9 & 0.303 & 0.895 & 0.756 & 0.844 \\
\hline IH1 & 0.571 & 0.855 & 0.921 & 0.784 \\
\hline IH3 & 0.334 & 0.952 & 0.976 & 0.841 \\
\hline IH4 & 0.248 & 0.932 & 0.963 & 0.830 \\
\hline IH5 & 0.315 & 0.957 & 0.971 & 0.879 \\
\hline PKU1 & 0.158 & 0.663 & 0.734 & 0.824 \\
\hline PKU10 & 0.223 & 0.820 & 0.643 & 0.791 \\
\hline PKU3 & 0.324 & 0.804 & 0.785 & 0.888 \\
\hline PKU4 & 0.171 & 0.782 & 0.719 & 0.814 \\
\hline PKU5 & 0.334 & 0.805 & 0.790 & 0.893 \\
\hline PKU7 & 0.603 & 0.583 & 0.623 & 0.724 \\
\hline PKU8 & 0.173 & 0.385 & 0.749 & 0.868 \\
\hline
\end{tabular}

Metode lain yang digunakan untuk menilai sebuah validitas diskriminan adalah dengan cara membandingkan akar AVE untuk setiap konstruk dengan korelasi antara konstruk yang lainnya dalam model. Model mempunyai validitas diskriminan yang cukup apabila akar AVE untuk setiap konstruknya lebih besar dari pada korelasi antara konstruk dengan konstruklainnya didalam model. Hasil dari nilai kriteria fornell larcker dapat dilihat pada Tabel 6

Diskriminan dengan kriteria fornell-larcker pada Tabel 6, menunjukkan nilai akar AVE tiap-tiap konstruk atau variabel hasil akar kuadrat AVE dari setiap variabel lebih besar dari korelasi antara dua atau lebih indikator variabel dalam model. Oleh karena itu, variabel dalam penelitian ini dapat dinyatakan memenuhi kriteria validitas diskriminan. 
Tabel 6

Nilai Fornell - Larcker

\begin{tabular}{lcccc}
\hline Variabel & Beban Kerja & $\begin{array}{c}\text { Budaya } \\
\text { Keselamatan } \\
\text { Pasien }\end{array}$ & $\begin{array}{c}\text { Implementasi } \\
\text { Handover } \\
\text { Perawat } \\
\text { Farmasi }\end{array}$ & $\begin{array}{c}\text { Peran Kepala } \\
\text { Unit }\end{array}$ \\
\hline \multicolumn{1}{c}{ Beban Kerja } & 0.904 & & & \\
\hline $\begin{array}{l}\text { Budaya } \\
\text { Keselamatan Pasien }\end{array}$ & 0.293 & 0.974 & & \\
\hline $\begin{array}{l}\text { Implementasi } \\
\begin{array}{l}\text { Handover Perawat } \\
\text { Farmasi }\end{array}\end{array}$ & 0.380 & 0.965 & 0.958 & \\
\hline Peran Kepala Unit & 0.330 & 0.917 & 0.871 & 0.831 \\
\hline
\end{tabular}

c. Uji Reliabilitas

Reliabilitas dapat menyatakan sejauh mana hasil atau pengukuran bisa dipercaya atau mampu diandalkan serta dapat memberikan hasil pengukuran yang relative konsisten setelah dilakukan beberapa kali pengukuran. Untuk mengukur sebuah tingkat reliabilitas variabel penelitian, maka digunakan koefisien alfa atau cronbachs alpha dan composite reliability. Item pengukuran dikatakan reliabel jika memiliki nilai koefisien alfa lebih besar dari 0.7. Berdasarkan hasil pengolahan data, maka diperoleh hasil uji reliabilitas pada Tabel 7.

Tabel 7

Uji Reliabilitas

\begin{tabular}{lcc}
\hline \multicolumn{1}{c}{ Variabel } & Cronbach's Alpha & Composite Reability \\
\hline Peran Kepala Unit & 0.924 & 0.939 \\
\hline Beban Kerja & 0.886 & 0.930 \\
\hline Implementasi Handover Perawat Farmasi & 0.970 & 0.978 \\
\hline Budaya Keselamatan Pasien & 0.942 & 0.957 \\
\hline
\end{tabular}

Tabel 7 menunjukkan, bahwa semua variabel dalam penelitian ini memiliki nilai cronbach alpha dan composit reliability $>0.7$. Sehingga hal ini, menunjukan bahwa konstruk variabel memiliki realibilitas data yang baik.
Dari hasil pengujian pada outer model, maka diperoleh model akhir penelitian berdasarkan pengukuranpengukuran, yang dapat diketahui pada Gambar 4. 


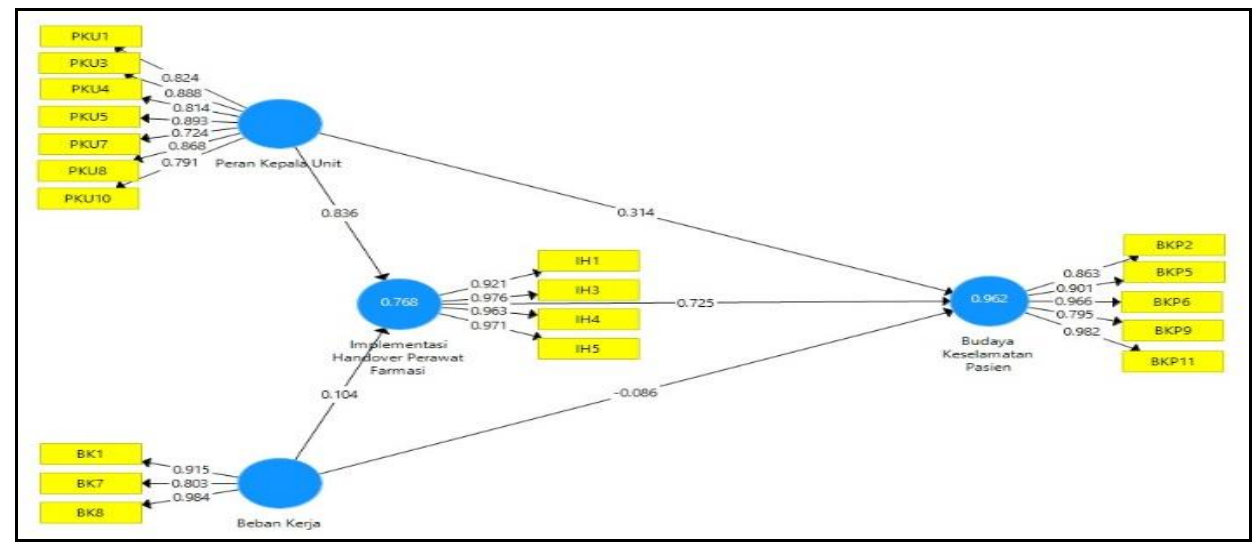

Gambar 4

Model Penelitian Final

\section{Kesimpulan}

Efektivitas implementasi clinical pathwaydi RS PMI Bogor $68 \%$ belum sesuai dari yang diharapkan yaitu $70 \%$, dikarena tidak semua multidisiplin terlibat dalam pengisisn clinical pathway. Hal ini karena audit dan evaluasi belum dilakukan dengan seharusnya. Efektivitas dapat tercapai bila semua multidisiplin dapat melaksanakan semua tugas yang didukung oleh sarana dan prasarana serta peraturan atau ketentuan yang dibuat sehingga dapat mencapai target dengan berorientasi pada hasil dan proses yang direncanakan.

Penelitian ini sejalan dengan penelitian (Claudia, 2018) Mengidentifikasi beberapa elemen dari penerapan jalur yang sukses, yang diyakini sebagai elemen dasar penting dari program Clinical Effectivnes.

\section{BIBLIOGRAFI}

Abdurrahman, M., \& Garcia, C. (2016). OnCall Geriatric Psychiatry "Safe Clinical Handover.” Google Scholar

Abela-Dimech, F., \& Vuksic, O. (2018). Improving The Practice Of Handover For Psychiatric Inpatient Nursing Staff. Archives Of Psychiatric Nursing, 32(5), 729-736. Google Scholar

Achrekar, M., Murthy, V., Kanan, S., Shetty, R., Nair, M., \& Khattry, N. (2016).
Introduction Of Situation, Background, Assessment, Recommendation Into Nursing Practice: A Prospective Study. Asia-Pacific Journal of Oncology Nursing, 3(1), 45. Google Scholar

Ahrq. (2014). Hospital Survey On Patient Safety Culture: User Comparative Databased Report. Google Scholar

Arikunto, S. (2010). Prosedur Penelitian Suatu Pendekatan Praktik. 2010. Jakarta: Rineka Cipta. Google Scholar

Cecep Triwibowo, Sulhah Yuliawati, \& Nur Amri Husna. (2016). Hand Over Sebagai Upaya Peningkatan Keselamatan Pasien Di Rumah Sakit. Jurnal Keperawatan Soedirman, 11(2), 76-80. Google Scholar

Claudia, M. (2018). The Influence Of Perceived Organizational Support, Job Satisfaction And Organizational Commitment Toward Organizational Citizenship Behavior (A Study Of The Permanent Lecturers At University Of Lambung Mangkurat, Banjarmasin). Journal Of Indonesian Economy And Business (Jieb), 33(1), 23-45. Google Scholar

Hasyim, \& Anindita, R. (2009). Prinsip Prinsip Dasar Metode Riset Bidang Pemasaran (1st Ed.). Jakarta: UieuUniversity Press. Google Scholar 
Pengaruh Peran Kepala Unit dan Beban Kerja terhadap Budaya Keselamatan Pasien Melalui Implementasi Handover Perawat-Farmasi

Indrawati. (2015). Metode Penelitian Manajemen Dan Bisnis Konvergensi Teknologi Komunikasi Dan Informasi. Bandung: Aditama. Google Scholar

Iom. (2009). To Err Is Human. In Pharmaceutical Journal (Vol. 283, Issue 7582). Google Scholar

Mardis, T., Mardis, M., Davis, J., Justice, E. M., Holdinsky, S. R., Donnelly, J., Ragozine-Bush, H., \& Riesenberg, L. A. (2016). Bedside Shift-To-Shift Handoffs A Systematic Review Of The Literature. Journal Of Nursing Care Quality, 31(1), 54-60. Google Scholar

National Clinical Effectiveness Commitee. (2014). Communication (Clinical Handover) In Maternity Services. Department Of Health, 5. Google Scholar
Peraturan Menteri Kesehatan Ri. (2011). Peraturan Menteri Kesehatan Republik Indonesia No 1691/Menkes/Per/Viii/2011 Tentang Keselamatan Pasien Rumah Sakit. Phys. Rev. E. Google Scholar

Sugiyono. (2013). Metode Penelitian Manajemen. Alfabeta. Google Scholar

Sugiyono. (2016). Metode Penelitian Kuantitatif, Kualitatif Dan $R \& D$. Alfabeta. Google Scholar

Yu, Z., Zhang, Y., Gu, Y., Xu, X., \& Mcarthur, A. (2017). Pediatric Clinical Handover: A Best Practice Implementation Project. Jbi Database Of Systematic Reviews And Implementation Reports, 15(10), 25852596. Google Scholar

\section{Copyright holder:}

Aini Nadhifah, Rokiah Kusumapradja, Nofierni (2022)

First publication right:

Jurnal Health Sains

This article is licensed under:

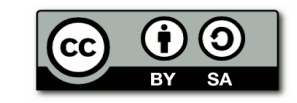

